\title{
Electromyographic recordings of the lateral pterygoid muscle in activator treatment of class II, division 1 malocclusion cases
}

\author{
Hans Jörg Auf der Maur \\ Klinik für Kieferorthopädie der Universität Bern, Switzerland
}

Summary. The mode of action of the Herren activator is explained and the function of the lateral pterygoid muscle is analysed.

In two monozygotic twins it was demonstrated, by means of electromyographic recordings, that the activator acts as a splint. The protruded position of the mandible when wearing the activator did not depend on activity of the lateral pterygoid muscle. Mandibular growth was marked during activator treatment which is in accordance with the views of several authors who maintain that the activator produces a significant increase in mandibular growth rate. It was demonstrated that the mandibular growth rate depends on the width of the construction bite.

Andresen, Häupl et al. maintained that wearing an activator stimulates jaw movements and produces increased activity of the masticatory muscles. However, other workers have not agreed with this concept. Gerber (1957) observed that sleeping patients wearing activators showed an almost total lack of mandibular macro movements. The results of Herren's investigations (1953, 1954, 1955, $1956,1959)$ also failed to confirm the views of Andresen and Häupl. On the contrary Herren (1979) showed that the activator acts as a splint keeping the mandible in the protruded position and that it influences the natural balance, in the rest position, of the muscles protruding and retracting the mandible. When the activator is in place the retractor muscles are tenser because their insertion points are farther apart than they

Paper presented at the 55th Congress of the European Orthodontic Society, Barcelona, Spain, 1979. would be in the normal rest position, and the myotatic reflex increases their tone as well as the tension of the elastic fibres. The retractor muscles try to restore the mandible to its habitual rest position but this is prevented by the activator. The force of the retracting muscles, transmitted to the splint, pushes the teeth and the alveolar process backwards in the upper jaw and in a forward direction in the lower jaw (Fig. 1). Graf (1962) demonstrated this

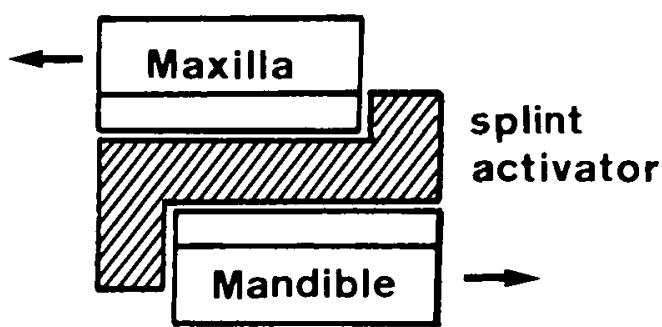

Figure 1 Splint effect of the activator. 


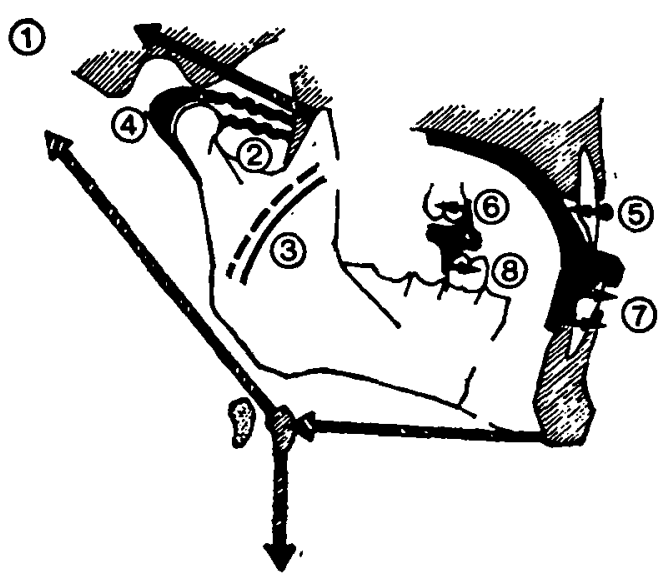

Figure 2 Sagittal and vertical changes in the masticatory system induced by the activator in the relaxed sleeping patient (from Herren, P. 1979).

influence on the muscle balance and he showed that the strength of the force was proportional to the sagittal width of the construction bite.

During sleep, with the activator in place, the retractor muscles are tenser and their antagonists, the lateral pterygoid muscles, are relaxed (Fig. 2 [2]). During the day when the appliance is not in place the mandible adopts a resting position with the muscle forces balanced.

The effects of the activator on this balanced position can be observed clinically. A few weeks after the insertion of the appliance the 'speech phenomenon' (Herren, 1965) can sometimes be observed. This is a forward shift of the mandible during vertical movement, distinguished by the decreased horizontal distance between the edges of the upper and lower incisors. The original morphological tooth/jaw relationship remains unchanged in the centric occlusion (CO) and centric relation (CR). The phenomenon is reversible and is observed in the morning rather than in the evening.

Sometimes, after an activator has been worn for several weeks, a constantly repeated clenching of the teeth in a position ahead of the original centric occulsion can be seen, although the mandible can still be pushed back into the former centric occlusion. This is a functional positional reaction.
After continued activator treatment for a further two to three months a fixed morphological change of the intercuspidation (relative to the original centric relation) towards a normal sagittal relationship may be observed.

The initial movement of the mandible required to insert the activator involves lateral pterygoid muscle activity, but the protruded position of the mandible is maintained during the night by the activator and does not require any muscular activity in the forward direction (Ahlgren, 1978).

The present electromyographic investigation was undertaken to study the behaviour of the lateral pterygoid muscle during activator therapy.

\section{Preliminary studies}

Electromyographic recordings of the lateral pterygoid muscle can be made extra-orally or intra-orally.

According to Ekholm and Siirilä the intra-oral method often leads to erroneous recording of the activity of the medial pterygoid muscle and may also result in haemorrhages in the pterygoid venous plexus. Furthermore, it is not suitable for use when a bimaxillary appliance is in place.

Complications also arise from the extraoral recording technique. The needle electrode passes through a profusely innervated and vascularized area and can cause haematoma or reversible paresis of branches of the facial nerve.

After considering the rather sparse existing literature (Moyers, 1950; Zenker, 1955; Carlsöö, 1956; Wölfel et al., 1957; Møller, 1966) and the special requirements of our tests, the extra-oral recording technique was chosen.

To establish an optimal intra-oral insertion technique, studies were made on three head preparations at the Anatomic Institute of the University of Berne. Ten autopolymerizing acrylic deposits of various colours were injected into the area where cranial and caudal portions of the lateral pterygoid muscles were assumed to be. The preparations were dissected and the position of the acrylic depots relative to the insertion point was 
assessed. Evaluation of the data resulted in a standard approach for the electromyographic investigations but individual modifications were necessary.

\section{Material}

Four boy's and four girls with a full Angle's Class II,' Division 1 malocclusion, aged 5 years 9 months to 10 years 10 months $(\bar{x}=9$ years 6 months) were treated with the Herren activator. Two of the boys (S.P. and S.St.) were monozygotic twins. The sagittal width of the construction bite was $4,6,8$, or $10 \mathrm{~mm}$ for each of two patients.

\section{Method}

In theory, activator therapy can be divided into seven phases - an O-phase before commencing treatment and six successive phases of reaction:

1. O-phase

2. speech phenomenon

3. functional positional reaction

4. M 1 fixed sagittal reaction of 1, 3,5 and

5. M $37 \mathrm{~mm}$ measured on the 6-year

6. M 5 molars of either side after deduc-

7. M 7 ting possible local mesial migration.

The transient speech phenomenon was observed and recorded in only one patient. The functional positional reaction is rare and was not seen in the examined patients, nor were phases $M 5$ and $M 7$ observable up to the time when the electromyographic investi- gations were discontinued. The occlusion was determined very carefully to eliminate Sunday bite and dual bite. The electromyographic recordings were made on the right lateral pterygoid muscle and on the muscular system of the floor of the mouth (mainly the anterior belly of the digastric muscle).

A bipolar needle electrode $(13 \mathrm{~K}, 0.65 \mathrm{~mm}$ diameter) was used for the electromyographic recording of the lateral pterygoid muscle and a surface electrode (Disa 13K 60) for the floor of the mouth. The Clinic of Neurology of the University of Berne made available a three channel electromyograph (type Disa 14 A 30) with optic and acoustic reproduction of the intensified signals. The recordings were made on photographic paper at a film speed of $5 \mathrm{~cm} / \mathrm{s}$. Each function was recorded for at least 10 seconds. Each recording routinely covered nine further functions (Table 1). The muscle functions A1-A6 were recorded without the activator in place and functions A7-A9 were recorded while the activator was being worn. With the exception of function $\mathrm{A} 7$, each function was preceeded by a phase of 'commanded' relaxation. In the results this phase is labelled $\mathrm{A} 1, \mathrm{~A} 2, \mathrm{~A} 3 \ldots$ A9; the phase of voluntary innervation is labelled $A^{\prime} 1, A^{\prime} 2, A^{\prime} 3 \ldots A^{\prime} 9$.

On the basis of the preliminary studies the electrode was inserted on a marked skin point, on average $18 \mathrm{~mm}$ ventrally of the largest protruberance of the right condyle and $9.5 \mathrm{~mm}$ caudally of the largest protruberance of the zygomatic bone. The average depth of

Table 1

Recorded muscle functions

Without activator

$\mathrm{A}^{1}=$ maximal occlusion

$\mathrm{A}^{2}=$ mandibular shift to the left

$\mathbf{A}^{3}=$ maximal protrusion of the mandible

$\mathrm{A}^{4}=$ counting movements from 1 to 10

$A^{5}=$ rest position approximated by humming the sound " $\mathrm{m}$ "

$A^{6}=$ slight protrusion of the mandible by about $3,5 \mathrm{~mm}$

Activator in situ

$A^{7}=$ "rest position"

$A^{8}=$ maximal occlusion

$A^{9}=$ maximal protrusion of the mandible isometric condition

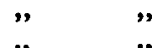

,

$" \quad \quad "$

,$\quad$, 
insertion was $29 \mathrm{~mm}$ (range $25-34 \mathrm{~mm}$ ). The angle between the needle and the frontal plane was on average $4^{\circ}$ (range $0-10^{\circ}$ ) and between the needle and the horizontal plane $23.5^{\circ}$ (range 20-25 ). Insertion was made from dorso-caudal to ventrocranial and by moving the mandible the position of the needle electrode was tested and positional errors were corrected by changing and depth angles of insertion.

It is difficult to decide whether the upper or the lower head of the lateral pterygoid muscle was recorded although the insertion technique was designed to hit the upper head of the muscle. However, this is irrelevant as far as the present investigations are concerned because the essential point was to show that the active propulsion of the mandible produces action potentials in the lateral pterygoid muscle whereas the protruded position maintained by the activator produces no electrical signals.

Inserting the activator after completing the recording A6 was only possible if the needle electrode was temporarily pulled back by about half or more of its length. Some patients used sedatives before the recording.

According to Puff (1971) the criteria for a valid judgement of the functional state of the measurable motor units surrounding the tip of the needle are fulfilled only if the patient is not tense and is able to relax his muscles completely after the insertion of the needle and after maximum voluntary innervation. The interference pattern of the action potentials depends largely on the position of the needle and on the co-operation of the patient. This is even more valid for the amplitude. Co- operation up to the age of 10 years is only obtainable for one or two test spots. From the left to the right Table 2 reflects the decreasing willingness of patients to undergo the often painful examination more than once. In order not to jeopardize subsequent activator therapy further recordings had to be abandoned. With the monozygotic twins S.P. and S.St we were able fortuitously to cariy out the recording programme longitudinally. With S.P., however, the program had to be discontinued in phase $M 3$ at A6.

\section{Results}

The eight patients were divided into four pairs with a sagittal width of construction bite of 4 , 6,8 and $10 \mathrm{~mm}$ respectively. The results show (Fig. 3) that the morphological reaction

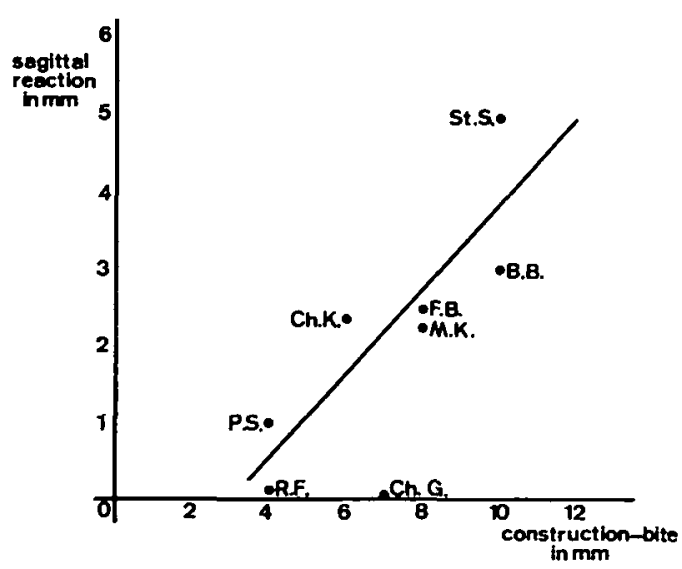

Figure 3 Sagittal reaction after 10 months of activator therapy related to the construction bite in 8 class II/1 cases.

Table 2 Division of the 9 completely and 6 partially successful recording programs into reaction phases and patients. The recording programs A7, A8 and A9 were carried out with the activator in place.

\begin{tabular}{|c|c|c|c|c|c|c|c|}
\hline Patient & O-phase & $\begin{array}{c}\text { Speech } \\
\text { phenomenon }\end{array}$ & $\begin{array}{l}\text { Functional } \\
\text { reaction }\end{array}$ & M 1 & M 3 & M 5 & M 7 \\
\hline $\begin{array}{l}\text { B.B. } \\
\text { B.F. } \\
\text { F.R. } \\
\text { G.Ch. } \\
\text { K.Ch. } \\
\text { K.M. } \\
\text { S.P. } \\
\text { S.St. }\end{array}$ & $\begin{array}{l}A^{1}-A^{6} \\
A^{1}-A^{9} \\
A^{1}-A^{9} \\
A^{1}-A^{9} \\
A^{1}-A^{5} \\
A^{1}-A^{6} \\
A^{1}-A^{9} \\
A^{1}-A^{9}\end{array}$ & $A^{1}-A^{9}$ & & $\begin{array}{l}A^{1}-A^{6} \\
A^{1}-A^{9} \\
A^{1}-A^{9}\end{array}$ & $\begin{array}{l}A^{1}-A^{6} \\
A^{1}-A^{9}\end{array}$ & & \\
\hline
\end{tabular}


depends on the sagittal width of the construction bite; the wider the construction bite the more effective is the morphological reaction.

The following illustrations of patients S.P. and S.St. are sections of the complete curves which are typical for the functions concerned. The illustration of the O-phase was left out since it corresponds to the electromyographic recordings of the reaction phase $M 1$ and $M$ 3. The description of the functions $\mathrm{A} 2$ and $\mathrm{A} 4$ were also left out because they were not relevant to the conclusions.

\section{Patient S.P.}

The electromyographic curves (Figs. 4, 5, 6, 7, 8) refer to the clinical reaction phase $M 1$ (improved sagittal relationship of $1 \mathrm{~mm}$ ) reached within six months of commencing treatment. The construction bite was $4 \mathrm{~mm}$. The curves show that the protruded position of the mandible (also under isometric conditions) requires activity of the lateral pterygoid muscle (Fig. 4 A'3, Fig. $5 \mathrm{~A}^{\prime} 6$, Fig. 8 $A^{\prime} 9$ ) but this is not the case for the protruded position of the mandible maintained by the activator in place (Figs. 6, 7, $8 \mathrm{A9}$ ).

\section{Patient S.St.}

Figs. 9, 10, 11, 12, 13 refer to the clinical reaction phases $M 1$ (improved sagittal relationship of $1 \mathrm{~mm}$ ) and $M 3$ (improved sagittal relationship of $3 \mathrm{~mm}$ ) achieved two and eight months respectively after commencing treatment with a construction bite of $10 \mathrm{~mm}$.

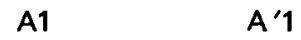

$A^{\prime} 1$

A3 $A^{\prime} 3$

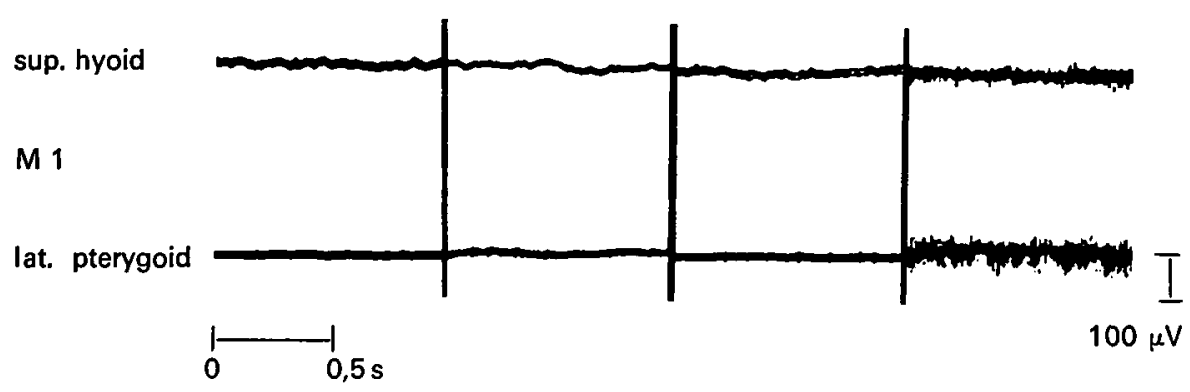

Figure 4 Maximal isometric clenching $\left(A^{\prime} 1\right)$ causes small, indistinct action potentials which may indicate activity from the more distant surroundings (temporal muscle). A3 points to individual potentials of distant motor units. In $A^{\prime} 3$ there are clearly distinguishable potentials of the lateral pterygoid muscle. There is also activity of the muscles of the floor of the mouth.

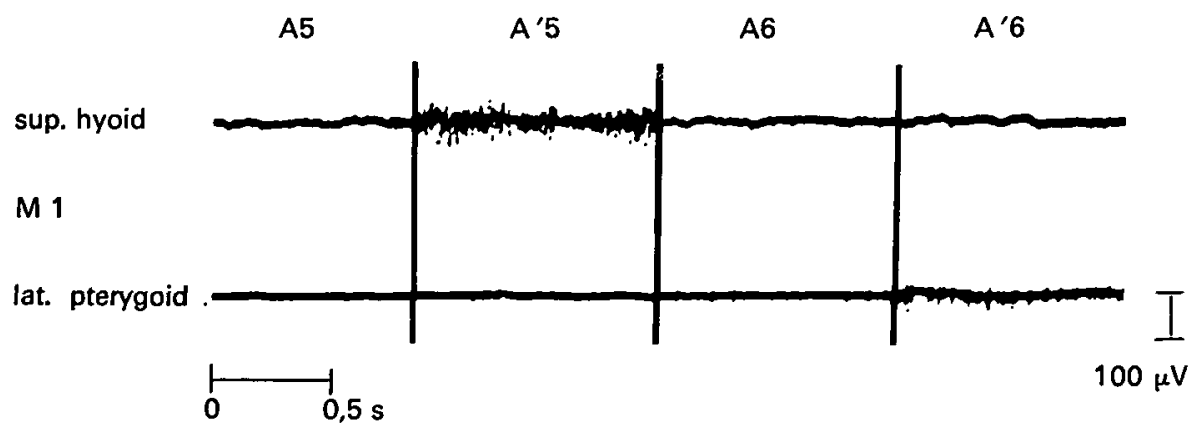

Figure 5 The ' $\mathrm{m}$ ' humming-sound ( $A^{\prime} 5$ ) causes sparse action potentials of the lateral ptyergoid muscle and a more intense activity of the muscles of the floor of the mouth. A'6 displays a weak voluntary innervation. The iso-electric line is clearly recognizable. 
A7

sup. hyoid

M1

lat. pterygoid

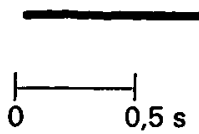

$100 \frac{T}{\mu V}$

Figure 6 The activator is in place, the mandible is in a protruded position caused by the construction bite. A short activity of the muscular system of the floor of the mouth is noticeable. No activity of the lateral pterygoid muscle.

A8

$A^{\prime} 8$

sup. hyoid

M 1

lat. pterygoid
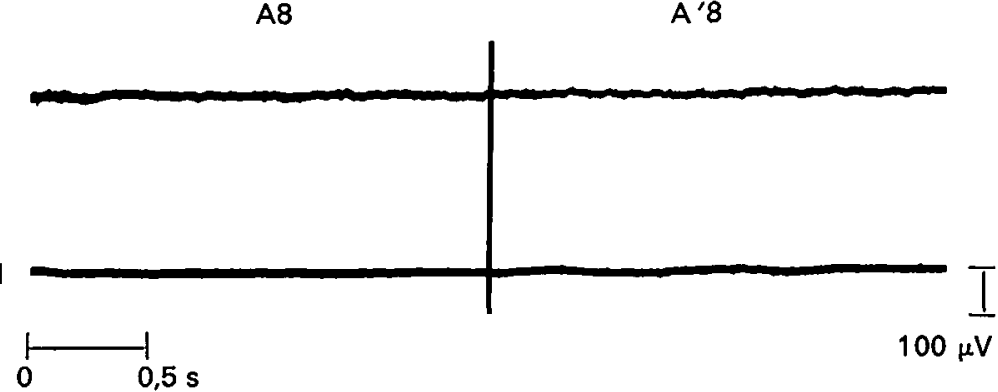

Figure 7 On request $\left(A^{\prime} 8\right)$ the patient bites strongly into the incisor groove of the activator (isometric clenching). This does not lead to any noticeable activity of the lateral pterygoid muscle.

A9

$A^{\prime} 9$

sup. hyoid

M 1
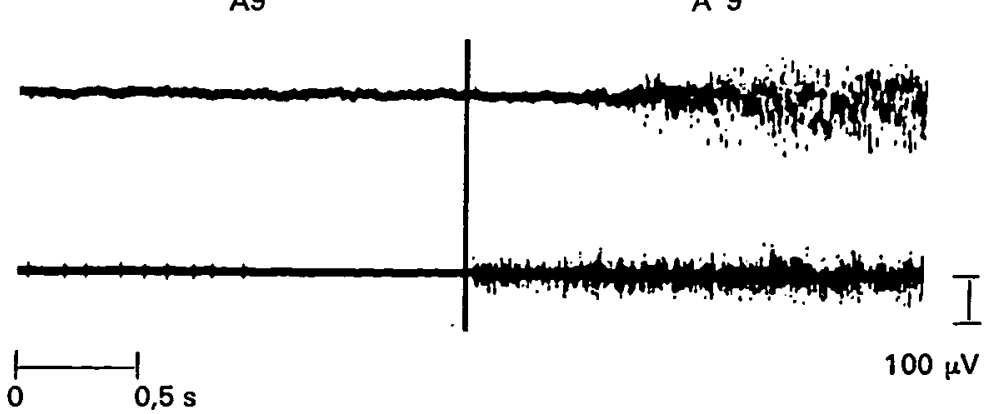

$100 \mu \mathrm{V}$

Figure 8 A9 shows sporadic potentials, which points to insufficient relaxation. $A^{\prime} 9$ illustrates that the patient is trying to push his mandible forward but is prevented from doing so by the incisor groove. The voluntary innervation of the lateral pterygoid muscle is intense. 


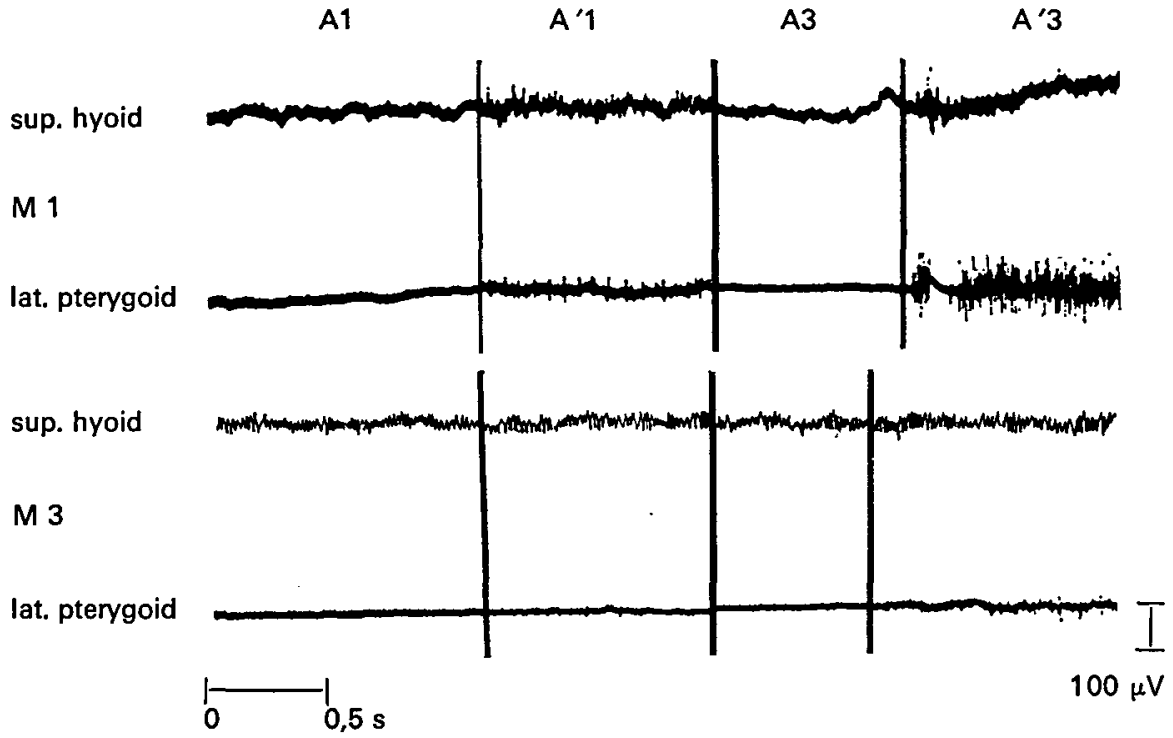

Figure $9 M$ 1: Isometric clenching ( $\left.A^{\prime} 1\right)$ leads to slight activity of the temporal muscle. This activity is not recorded from the lateral pterygoid muscle but as the tip of the needle is very close to the temporal muscle it is assumed to be the source of the activity. The position of the electrode is modified and isometric protrusion of the mandible $\left(\mathrm{A}^{\prime} 3\right)$ shows an intense activity of the lateral pterygoid muscle.

M 3: Maximal clenching ( $\left.A^{\prime} 1\right)$ causes individual action potentials in the lateral pterygoid muscle. Protrusion of the mandible $\left(\mathrm{A}^{\prime} 3\right)$ results in voluntary innervation of medium intensity in the lateral pterygoid muscle.

sup. hyoid

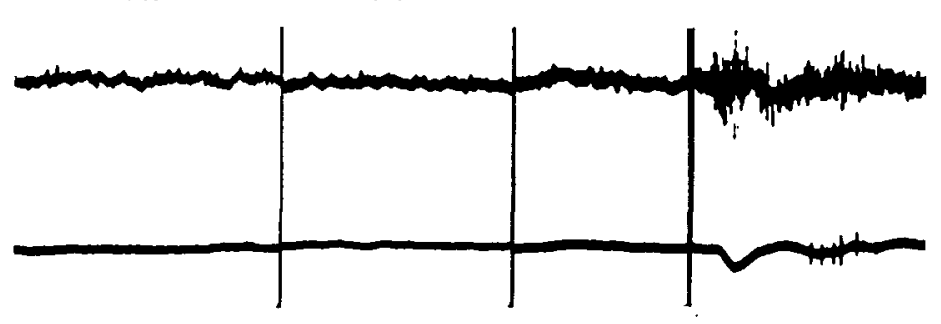

sup. hyoid

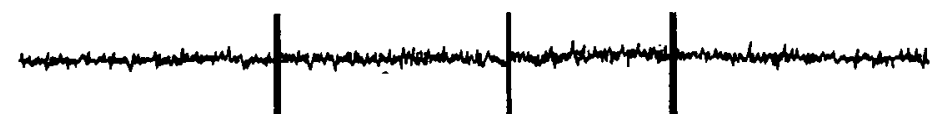

M 3

lat. pterygoid

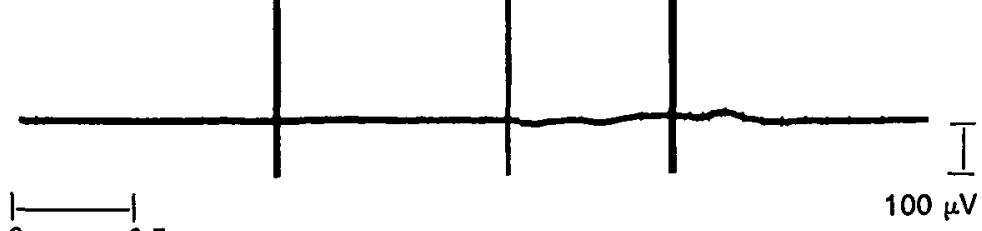

Figure 10 M 1: The ' $m$ ' sound (simulating the rest position of the mandible) does not cause any activity of the lateral pterygoid muscle $\left(A^{\prime} 5\right)$. With a slight propulsion of the mandible $\left(A^{\prime} 6\right)$ activity of the suprahyoid muscles starts. The lateral pterygoid muscle displays only few action potentials, which points to intermittent voluntary innervation.

M 3: With slight protrusion of the mandible $\left(A^{\prime} 6\right)$ the activity of the lateral pterygoid muscle is weak. 


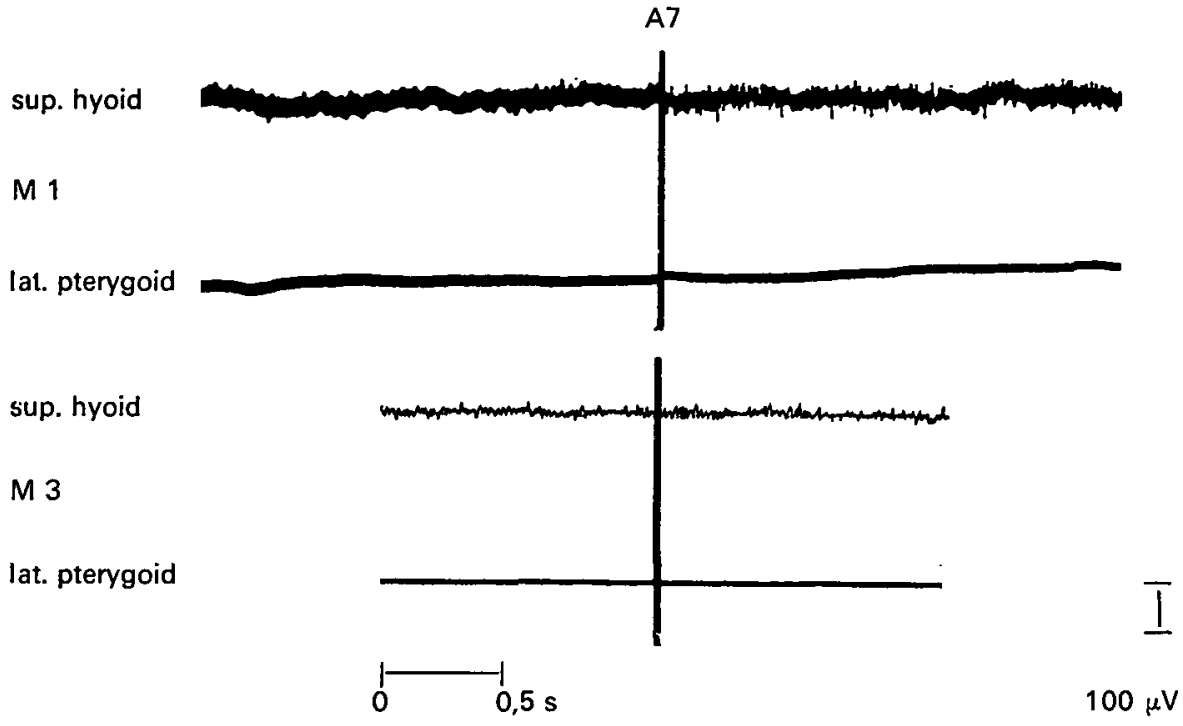

Figure $11 \quad M 1$ and M 3: The activator is in place. A7 shows a decreasing activity of the suprahyoid muscles from $M 1$ to $M 3$, and complete inactivity of the lateral pterygoid muscle.

sup. hyoid

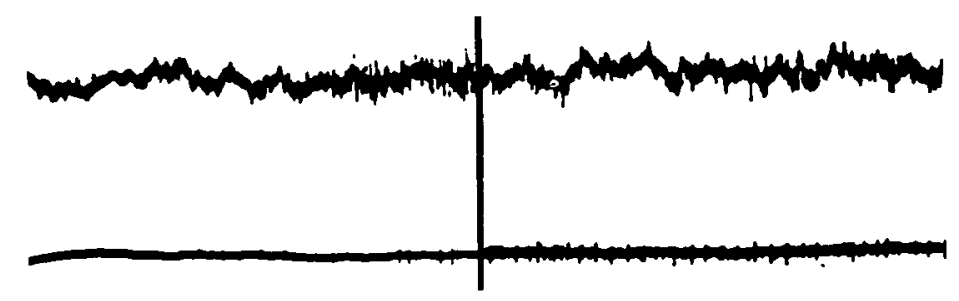

sup. hyoid
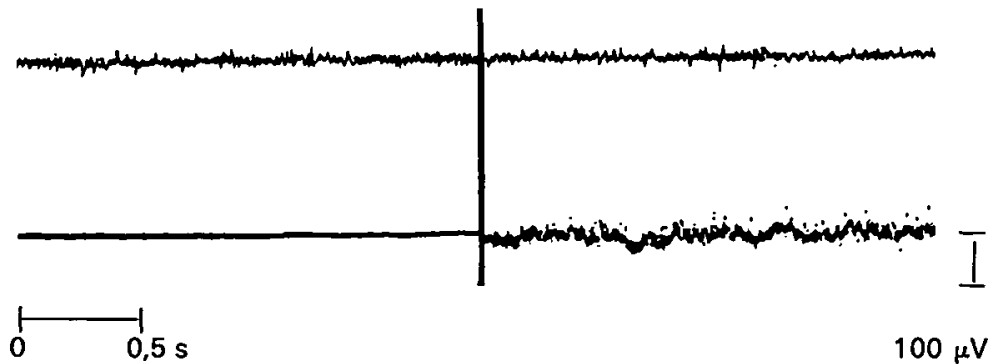

$100 \mu \mathrm{V}$

Figure $12 M$ 1: A8 as well as $A^{\prime} 8$ show inactivity. The isometric clenching (A'8) causes small potentials coming from the more distant surroundings (temporal muscle).

M 3: A8 displays only a few isolated potentials. The isometric clenching $\left(A^{\prime} 8\right)$ shows medium to strong innervation. The action potentials are obviously recorded from the temporal muscle. The position of the needle electrode is changed for the recording in Figure 13 and its correct position is checked. The suprahyoid muscles again show decreasing activity from M 1 to $M 3$. 


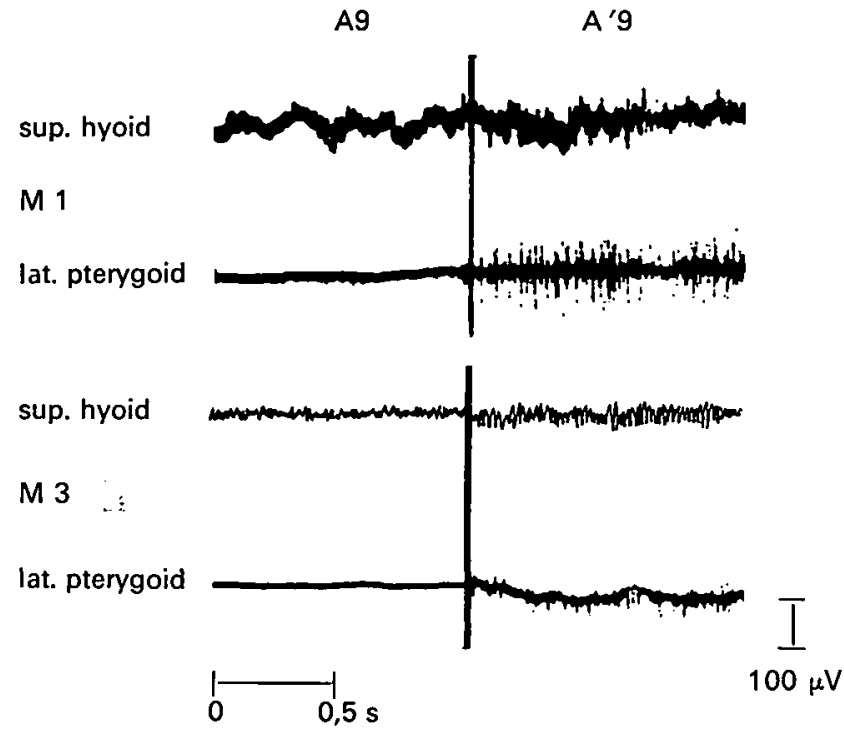

Figure 13 $M$ 1: Under isometric conditions the propulsion of the mandible $\left(A^{\prime} 9\right)$ leads to an intense voluntary innervation of the lateral pterygoid muscle.

M 3: A'9 shows a voluntary innervation of medium intensity of the lateral pterygoid muscle.

The suprahyoid muscles show the same activity/pattern as in Figures 11 and 12.

\begin{abstract}
Also in this case the activator maintains the protruded position of the mandible without any activity of the lateral pterygoid muscle being required (Figs. 11 A7, 13 A9).
\end{abstract}

\section{Discussion}

After active treatment patient S.P. showed an improved, and patient S.St. a normalized sagittal relationship. Using the cephalometric measuring method of Demisch (1973) it was found that the length of the mandible increased by $6 \mathrm{~mm}$ for S.P. and $9 \mathrm{~mm}$ for S.St. during treatment. The amount of increase that would have occurred without activator therapy is of course unknown. However, the monozygotic twin S.St. who had the wider construction bite showed the greater amount of mandibular growth.

At the age of 23 total mandibular growth of $22 \mathrm{~mm}$ in the sagittal direction measured from the O-phase was found in S.St. and 21.5 $\mathrm{mm}$ in S.P. The higher growth rate of S.St. during the treatment phase did not result in an increased final length of the mandible compared with S.P. The difference evened out by post-treatment sagittal mandibular growth in S.P.

Demisch (1973) and other investigators have shown a statistically significant increase in mandibular growth rates in patients treated with activators.

In the twin patients no activity of the lateral pterygoid muscle was needed to maintain the protruded position of the mandible while the activator was being worn. If this result is obtained in a wide awake child one can assume that it will certainly occur when the child is sleeping and relaxed. These results are contrary to the hypotheses of Petrovic et al. $(1974,1975)$ and Stutzmann and Petrovic (1975) that the lateral pterygoid muscle plays an important part in controlling condylar and mandibular growth. These authors used a hyperpropulsor in rats for eight to 12 hours daily and claimed that this effects a postural protruded position of the 
mandible through the contractile activity of the lateral pterygoid muscle. In normal animals this showed a stimulating effect on condylar growth but not in animals with a severed lateral pterygoid muscle and from this they concluded that if an orthodontic appliance does not lead to a postural forward position of the mandible conditioned by contractility, condylar growth is not stimulated.

The present authors find their hypothesis confirmed by electromyographic investigations by McNamara (1973a, b, 1975) who used a cast splint cemented on to the maxillary teeth of macaca mulatta monkeys with the occlusion opened by $2 \mathrm{~mm}$ and a forward shift of the articulation by $2 \mathrm{~mm}$. For the upper head of the muscle the electromyographic recordings show activity during movement (clenching and swallowing) as well as in the protruded position which is known as postural position. The appliance used by McNamara, through the change of the upper masticatory surfaces, leads to active propulsion of the mandible with each clenching movement. The electromyographic recordings show that the lateral pterygoid muscles are activated at the same time as the elevators but passive protrusion along the inclined plane of the overlays could theoretically arise from the activity of the elevators alone. However, the appliance acts by punctual active interruption of the rest position in contradistinction to the activator and, furthermore, the appliance is active for 24 hours in each day while the activator is only active for $8-10$ hours, the appliance being left out for 14-16 of each 24 hours.

The results from the two patients S.P. and S.St. indicate that the results of McNamara's electromyographic recordings of the lateral pterygoid muscle cannot be applied to the activator. Petrovic uses McNamara's results as confirmation of his hypothesis that the hyperpropulsor produces increased tension of these muscles which in turn leads to increased mitoses of prechondroblasts, i.e. stimulates condylar growth.

If the hyperpropulsor is only active when changing from the rest position into the protruded position it would be acting in effect in the same way as the splint worn by the monkeys in McNamara's experiments and in quite a different way to the activator which holds the mandible in a protruded position mechanically. If, however, the hyperpropulsor acts like the activator to maintain the forward position of the mandible mechanically it would appear that Petrovic's hypothesis concerning the role of the lateral pterygoid muscle should be reconsidered to exclude the possibility that increased mandibular growth rates in activator groups are due to the passive forward position of the mandible maintained by the appliance.

We share Petrovic's opinion (1978) that only exceptionally are single observations sufficient to explain a concept or a theory. However, the results of the present investigation do support Herren's theory about the mode of action of the activator.

\section{Acknowledgement}

The author is indebted to Professor Dr M. Mumenthaler, head of the Department of Neurology, who put at his disposal the electromyographic installation, and to Professor Dr H. P. Ludin for his technical help and advice with the experiments and interpretation of the recordings.

\section{Address for correspondence}

H. J. Auf der Maur,

Klinik für Kieferorthopädie der

Universität Bern,

Freiburg Strasse 7,

3010 Bern,

Switzerland.

\section{References}

Ahlgren, J. (1978). Early and late electromyographic response to treatment with activators. American Journal of Orthodontics, 74: 88-93.

Andresen, V., Häupl, K. and Petrik, L. (1957). Funktionskieferorthopädie. 6. Auflage J. A. Barth, Munchen. 
Carlsöö, S.(1956). An electromyographicstudy of the activity and an anatomic analysis of the mechanism of the lateral pterygoid muscle. Acta anatomica, 26: 339-351.

Demisch, A. (1973). Auswirkungen der Distalbisstherapie mit dem Aktivator auf das Gesichtsskelett. Schweizerische Monatsschrift für Zahnheilkunde, 83: 1072-1092.

Gerber, M. (1957). Beobachtungen an schlafenden Aktivatorträgern. Fortschritte der Kieferorthopädie, 18: 205-232.

Graf, E. J. (1962). Funktionelle Kräfte bei bimaxillärer Regulationsapparatur. Medizinische Dissertation, Bern.

Herren, P. (1953). Die passive Haltung und Bewegung des Unterkiefers. Schweizerische Monatszeitschrift für Zahnheilkunde, 63: 829-879.

Herren, P. (1954). Stellungnahme zu K. Häupls 'Gedanken und Erwägungen . . .' Schweizerische Monatszeitschrift für Zahnheilkunde, 64: 862-879.

Herren, P. (1955). Zur Praxis des Aktivators. Schweizerische Monatszeitschrift für Zahnheilkunde, 65: 213-235.

Herren, P. (1956). Ueber die Reizqualitäten kieferorthopädischer Apparate. Schweizerische Monatszeitschrift für Zahnheilkunde, 66: 13-30.

Herren, P. (1959). The activator's mode of action. American Journal of Orthodontics, 45: 512-527.

Herren, P. (1965). Sagittaler Bissausgleich im Lichte einiger muskelfunktioneller Beobachtungen. Studieweek, Nederlandse Vereinigung voor Orthodontische Studie, 152182.

Herren, P. (1979). Das Wirkungsprinzip des Distalbissaktivators. Fortschritte der Kieferorthopädie, 41 : 308-329.

Herren, P., Weber, J. and Müller, P. (1972). The palpatation phenomenon of the condyle at the external auditory meatus during treatment of class II/1 anomalies by means of activator. Transactions of the European Orthodontic Society, 339-351.

McNamara, J. A. (1973a). Neuromuscular and skeletal adaptions to altered function in the orofacial region. American Journal of Orthodontics, 64: 578-606.
McNamara, J. A. (1973b). The independent functions of the two heads of the lateral pterygoid muscle. American Journal of Anatomy, 138: 197-206.

McNamara, J. A. (1975). Functional adaptations in the temporo-mandibular joint. Dental Clinics of North America, 19: 457-183

Møller, E. (1966). The chewing apparatus. Acta physiologica scandinavica, 69 supplementum 280, Copenhagen.

Moyers, R. E. (1950). An electromyographic analysis of certain muscles involved in temporo-mandibular movement. American Journal of Orthodontics, 36: 481-515.

Petrovic, A., Stutzmann, J., Oudet, C. and Gasson, N. (1974). Kontrollfaktoren des Kondylenwachstums. Fortschritte der Kieferorthopädie, 35: 347-364.

Petrovic, A., Gasson, N. and Oudet, C. (1975). Wirkung der übertriebenen posturalen Vorschubhaltung des Unterkiefers auf das Kondylenwachstum der normalen und der mit Wachstumshormon behandelten Ratte Fortschritte der Kieferorthopädie, 36: 86-97.

Petrovic, A. (1978). La conception cybernétique de la croissance du squelette craniofacial et de l'art de l'influencer. Thesen an der Jahrestagung des Club international de morphologie maxillo-faciale, Genf.

Puff, K. H. (1971). Die klinische Elektromyographie in der Differentialdiagnose von Neuro- und Myopathien. Schriftenreihe Neurologie, Band 7, New York.

Stutzmann, J. and Petrovic, A. (1975). Tierexperimentelle Untersuchungen über Zusammenhänge zwischen Zunge, Musculus pterygoideus lateralis, mandibulärem Kondylenknorpel und Gaumennaht. Fortschritte der Kieferorthopädie, 36: 354373.

Woefel, J. B., Hickey, J. C. and Rinean, L. L. (1957). Electromyographic evidence supporting the mandibular hinge axis theory. Journal of Prosthetic Dentistry, 7: 361-367.

Zenker, W. and Zenker, A. (1955). Die Tätigkeit der Kiefermuskulatur und ihre elektromyographische Analyse. Zeitschrift für Anatomie und Entwicklungsgeschichte, 119: 174-200. 